\title{
Lobectomy in patients with cystic fibrosis
}

\author{
Shahid I Sheikh $M D^{1}$, Karen McCoy MDํㄹ , Nancy A Ryan-Wenger PhD RN², \\ Alpa Patel $M D^{1,3}$, Stephen Kirkby $M D^{1,3}$
}

\begin{abstract}
SI Sheikh, K McCoy, NA Ryan-Wenger, A Patel, S Kirkby. Lobectomy in patients with cystic fibrosis. Can Respir J 2014;21(4):e63-e66.
\end{abstract}

BACKGROUND: Some patients with cystic fibrosis (CF) develop severe but localized lung disease or recurrent hemoptysis/pneumothorax refractory to conventional medical therapies.

METHODS: The outcomes of lung resection in patients with CF and worsening localized lung disease or recurrent hemoptysis/pneumothorax refractory to conventional therapy $(n=15)$ were evaluated by reviewing the medical records of all patients with CF followed at the CF Center at Nationwide Children's Hospital (Columbus, Ohio, USA), who underwent lobectomy over a 15-year period (1998 to 2012).

RESULTS: The median age of the 15 patients (93\% Caucasian) was 20 years (range two to 41 years) and their mean forced expiratory volume in $1 \mathrm{~s}$ $\left(\mathrm{FEV}_{1}\right)$ was $59.5 \%$ of predicted one year before surgery. Three patients died within two years after lobectomy; all three deaths occurred in patients with an $\mathrm{FEV}_{1} \leq 40 \%$ of predicted before surgery. There were no significant changes in mean height, weight, body mass index, hospital admissions or antibiotic use over time. The mean $\mathrm{FEV}_{1}$ decreased over time. Compared with at surgery, decline in $\mathrm{FEV}_{1}$ in the year before surgery was $-5.4 \%(\mathrm{P}=0.024)$ and decline in the year after surgery was $-1.3 \%(\mathrm{P}=0.513)$; however, the difference in the rate of decline was not statistically significant.

CONCLUSION: In patients with CF and localized worsening bronchiectasis and/or recurrent hemoptysis/pneumothorax, lobectomy carried a significant risk of mortality, especially in patients with $\mathrm{FEV}_{1} \leq 40 \%$ of predicted, and should only be considered when all other measures fail.

Key Words: Cystic fibrosis; Lobectomy; Pulmonary function tests

Drogressive lung disease is the main cause of morbidity and mortality in children and adults with cystic fibrosis (CF) (1). Pulmonary manifestations of $\mathrm{CF}$ are characterized by bronchiectasis, obstructive airflow and chronic airway inflammation. Although most patients develop progressive multifocal lung disease, a small proportion develops severe but localized lung disease, with bronchiectasis refractory to medical therapies. Some of these patients are also at high risk for recurrent hemoptysis or pneumothorax (PTX), both of which are potentially life-threatening acute complications. Surgical resection (partial or full lobectomy) may be a treatment option for localized severe bronchiectasis and/or atelectasis, or in cases of severe hemoptysis refractory to conservative management. The goal of the present study was to review the outcomes of lung resection in patients with CF with either worsening localized lung disease or recurrent hemoptysis/ PTX who failed standard therapies. Improvement, if any, was quantified by comparing changes in lung function and pulmonary disease activity within two years after surgery.

\section{METHODS}

The medical records of all patients with CF followed at the CF Center at Nationwide Children's Hospital (Columbus, Ohio, USA) who underwent lobectomy over a 15-year period (1998 to 2012) and were followed for at least one year before surgery $(n=15)$ were reviewed. The present study was approved by the local institutional review board (IRB11-00670). Outcomes of the procedure were measured by

\section{La lobectomie chez les patients atteints de fibrose kystique}

HISTORIQUE : Certains patients atteints de fibrose kystique (FK) acquièrent une maladie pulmonaire grave mais localisée ou une hémoptysie ou un pneumothorax réfractaires à la pharmacothérapie classique.

MÉTHODOLOGIE : Les chercheurs ont évalué les résultats de la résection pulmonaire chez des patients atteints de FK et l'aggravation de la maladie pulmonaire localisée ou de l'hémoptysie ou du pneumothorax récurrents réfractaires au traitement classique $(n=15)$ par un examen des dossiers médicaux de tous les patients atteints de FK suivis au centre de FK du Nationwide Children's Hospital de Columbus, en Ohio, aux États-Unis, qui ont subi une lobectomie, et ce, sur une période de 15 ans (de 1998 à 2012).

RÉSULTATS : Les 15 patients ( 93 \% de blancs) avaient un âge médian de 20 ans (plage de deux à 41 ans) et un volume expiratoire maximal par seconde (VEMS) moyen de 59,5\% de la valeur prévue un an avant l'opération. Trois patients, qui présentaient tous un VEMS égal ou inférieur à $40 \%$ de la valeur prévue avant l'opération, sont décédés dans les deux ans suivant la lobectomie. Les chercheurs n'ont remarqué aucun changement significatif de la moyenne de taille, de poids, d'indice de masse corporelle, d'hospitalisation ou d'utilisation d'antibiotiques au fil du temps. Le VEMS moyen diminuait au fil du temps. Par rapport à celui observé au moment de l'opération, le VEMS diminuait de 5,4\% $(\mathrm{P}=0.024)$ dans l'année précédant l'opération, et de $1,3 \%(\mathrm{P}=0,513)$ dans l'année suivant l'opération. Cette différence du taux de diminution n'était toutefois pas significative.

CONCLUSION : Chez les patients atteints de FK et d'une aggravation localisée de la bronchiectasie ou d'une hémoptysie ou d'un pneumothorax récurrents, la lobectomie s'associait à un risque important de mortalité, particulièrement chez les patients dont le VEMS était égal ou inférieur à $40 \%$ de la valeur prévue. Il faudrait l'envisager seulement après l'échec de toutes les autres mesures.

changes, if any, in the mean weight, body mass index (BMI), number of hospital admissions, and pulmonary exacerbations requiring intravenous antibiotics and/or oral/nebulized antibiotics over time.

The mean percent predicted forced expiratory volume in $1 \mathrm{~s}$ $\left(\mathrm{FEV}_{1}\right)$ was compared at one year prelobectomy, immediately before lobectomy, one year postlobectomy and two years postlobectomy. One patient was two years of age and not able to perform spirometry; thus, not included in the pulmonary function testing (PFT) data. All remaining patients were able to perform spirometry. Measurements performed within one month of pulmonary exacerbations of CF were not used. Changes in these parameters over time were compared for the entire sample and also for subgroups of patients based on severity of lung disease, survival after surgery and indication for lobectomy (worsening localized lung disease versus PTX/hemoptysis). Progressive localized lung disease was defined as worsening bronchiectasis primarily involving one lobe, which, in spite of multiple antibiotic courses and daily chest therapy, was responsible for frequent pulmonary exacerbations and continued worsening of lung function. Recurrent hemoptysis/PTX refractory to conventional therapy was defined as severe bronchiectasis in addition to recurrent episodes of hemoptysis primarily involving one lobe that failed to resolve with multiple antibiotic courses and bronchial artery embolization. Similarly, recurrent refractory PTX was defined as recurrent PTX primarily involving one lobe that recurred in spite of frequent antibiotic courses and chest tube placements. Patients were considered to be refractory to conventional

${ }^{1}$ Division of Pulmonary Medicine, Department of Pediatrics, Ohio State University College of Medicine, Nationwide Children's Hospital;

${ }^{2}$ Department of Nursing Research, Nationwide Children's Hospital; ${ }^{3}$ Department of Internal Medicine, Ohio State University College of

Medicine, Columbus, Ohio, USA

Correspondence: Dr Shahid I Sheikh, Division of Pulmonary Medicine, Department of Pediatrics, Ohio State University College of Medicine,

ED 444, Nationwide Children's Hospital, 700 Children's Drive, Columbus, Ohio 43205, USA. Telephone 614-722-3463,

fax 614-722-4755, e-mail shahid.sheikh@nationwidechildrens.org 


\begin{tabular}{|c|c|}
\hline \multicolumn{2}{|l|}{ Characteristic } \\
\hline Age at procedure, years & $20.6 \pm 10.5$ \\
\hline Current age, years & $25.7 \pm 11.3$ \\
\hline Pediatric intensive care unit stay, days & $7.3 \pm 17.5$ \\
\hline Hospital stay, days & $18.3 \pm 19.4$ \\
\hline Chest tube, days & $8.5 \pm 6.1$ \\
\hline \multicolumn{2}{|l|}{ Sex } \\
\hline Male & $6(40)$ \\
\hline Female & $9(60)$ \\
\hline \multicolumn{2}{|l|}{ Race } \\
\hline Black & $1(6.7)$ \\
\hline White & $14(93.3)$ \\
\hline delta F 508 homozygote $(n=11)$ & $8(72.7)$ \\
\hline \multicolumn{2}{|l|}{ Sputum colonization at surgery } \\
\hline Pseudomonas aeruginosa & $14(93.3)$ \\
\hline Staphylococcus aureus & $10(67.0)$ \\
\hline Methicillin-resistant $S$ aureus & $3(20.0)$ \\
\hline Pancreatic insufficiency & $15(100)$ \\
\hline Cystic fibrosis-related diabetes mellitus & $5(33.3)$ \\
\hline Gastroesophogeal reflux & $9(60.0)$ \\
\hline \multicolumn{2}{|l|}{ Indication for lobectomy } \\
\hline Worsening condition & $10(67.0)$ \\
\hline Recurrent hemoptysis/pneumothorax & $5(33)$ \\
\hline \multicolumn{2}{|l|}{ Lobe removed } \\
\hline Upper right & $12(80.0)$ \\
\hline Middle right & $2(13.4)$ \\
\hline Upper left & $1(6.7)$ \\
\hline Deceased & $3(20.0)$ \\
\hline
\end{tabular}

Data presented as mean \pm SD or $n(\%)$

therapy if, in spite all above mentioned therapies, progressive worsening of underlying lung disease occurred. Lung disease was defined as severe if mean $\mathrm{FEV}_{1}$ one year before surgery was $\leq 40 \%$ of predicted. The mean percent $\mathrm{FEV}_{1}$ was calculated using Knudson standards.

Data analysis

Descriptive statistics were used to describe the demographic and clinical characteristics of the sample. Changes in clinical variables over time and between patients with severe lung disease or less severe lung disease at one year before lobectomy were analyzed using repeatedmeasures ANOVA, paired $t$ tests or independent $t$ tests, or MannWhitney tests as appropriate. Statistical significance was set at $\mathrm{P} \leq 0.05$.

\section{RESULTS}

At this particular CF centre $(n=520), 15$ patients underwent lobectomy in the 15-year period from 1998 to 2012 and were included in the study (Table 1). All patients underwent an open procedure. There were 10 adults and five children (six male, nine female), 93\% were Caucasian and their ages ranged from two to 41 years of age (mean 20.6 years of age) at the time of surgery. Two patients died during the immediate postoperative period (at two weeks and two months postlobectomy) and one patient died in the second year postlobectomy. All three deaths occurred in patients with severe lung disease $\left(\mathrm{FEV}_{1} \leq 40 \%\right.$ of predicted). The overall one-year survival rate of the group was $87 \%$ (13 of 15 patients) while the overall two-year survival rate was $80 \%$ (12 of 15 ).

The indication for surgery in $10(67 \%)$ patients was progressive localized bronchiectasis; the remaining five $(33 \%)$ underwent surgery due to either recurrent hemoptysis $(n=1)$ or recurrent pneumothorax $(n=3)$, or both $(n=1)$ that were refractory to conventional therapy. Among these five patients, four underwent emergency surgery. Twelve of $15(80 \%)$ patients had the right upper lobe removed, two had the

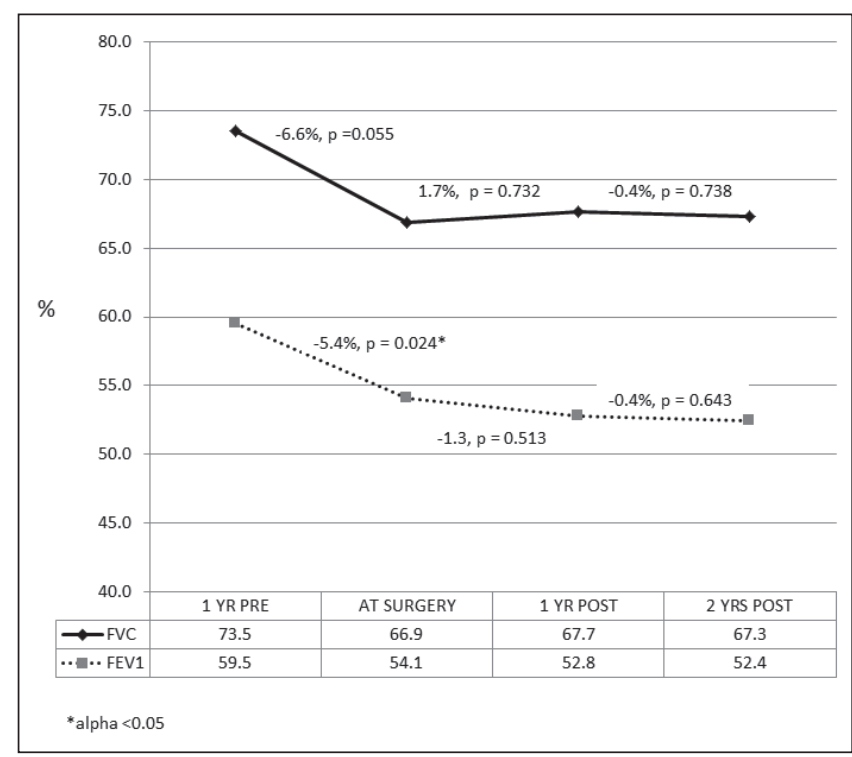

Figure 1) Rates of change in pulmonary function tests over three time periods in cystic fibrosis patients who underwent a lobectomy $(n=14) . F E V_{1}$ Forced expiratory volume in $1 \mathrm{~s}$; FVC Forced vital capacity; YRS Year(s)

right middle lobe and one had the left upper lobe removed. The hospital stay ranged from six to 85 days (median 14 days), intensive care unit stays ranged from one to 70 days (median two days), and the number of days with chest tubes ranged from three to 25 (median seven days). One patient required lung transplantation several years after lobectomy. Of the 15 patients in the study, at the time of surgery, five had a diagnosis of CF-related diabetes mellitus, and one patient had an altered glucose tolerance test. All patients had pancreatic insufficiency and were receiving replacement pancreatic enzymes (Table 1).

Fourteen patients had respiratory colonization with Pseudomonas aeruginosa diagnosed with either sputum or throat cultures. None of the patients had positive acid-fast cultures for Mycobacterium. Genotype was available for 11 patients and all had the delta F 508 gene and, among these, eight were homozygous for delta F 508 (Table 1).

One patient was two years of age and underwent lobectomy for localized worsening lobar bronchiectasis. Chest x-ray and chest computed tomography scan of the chest were not suggestive of any congenital anomaly (ie, sequestered lobe, congenital adenomatoid malformation or tracheal bronchus) or foreign body. Pathology reports from the lung tissue also revealed severe bronchiectasis without any congenital lung defects.

In total, there were no significant changes in mean height, weight, BMI, number of hospital admissions, or oral and intravenous antibiotic use over the three time periods (first year presurgery compared with at surgery, at surgery compared with first year postsurgery and first year postsurgery compared with second year postsurgery) (Table 2). There was a trend toward improvement in mean hospital admissions/ year after surgery but the difference was not significant. Mean FEV decreased throughout the three time periods. The mean $( \pm$ SD) FEV 1 at one year before surgery was $59.5 \pm 24 \%$ of predicted, which at surgery decreased to $54.1 \pm 25.1 \%$ of predicted $(\mathrm{P}=0.024)$ (Table 2$)$. $\mathrm{FEV}_{1}$ at one year after surgery was $52.8 \pm 24.8 \%$ and at two years after surgery was $52.4 \pm 25.1 \%$ (Figure 1, Table 2). Paired comparisons indicated significant decrease in mean $\mathrm{FEV}_{1}$ from one year pre- to at surgery $(-5.4 \% ; \mathrm{P}=0.024)$ (Figure 1, Table 2). Decline in mean $\mathrm{FEV}_{1}$ in first year after the surgery was $-1.3 \%$ and in the second year after the surgery was $-0.4 \%$; neither were statistically significant (Figure 1 ). Rate of decline in mean $\mathrm{FEV}_{1}$ at surgery, at one year and at two year after the surgery were compared using paired $t$ tests and the differences were not statistically significant. 
TABLE 2

Changes in clinical course over four time periods of the patients with cystic fibrosis who underwent lobectomy $(n=14)$

\begin{tabular}{lcccc}
\hline & \multicolumn{4}{c}{ Surgery } \\
\cline { 2 - 5 } & 1 year pre & At surgery & 1 year post & 2 year post \\
\hline $\mathrm{FEV}_{1}, \%$ pred & $59.5 \pm 24.3^{*}$ & $54.1 \pm 25.1^{*}$ & $52.8 \pm 24.8$ & $52.4 \pm 25.1$ \\
$\mathrm{FVC} \%$ & $73.5 \pm 21.1$ & $66.9 \pm 22$ & $67.7 \pm 20.5$ & $67.3 \pm 21.4$ \\
$\mathrm{FEF}_{25-75}, \%$ & $44.5 \pm 36.5$ & $40.8 \pm 36.1$ & $35.5 \pm 33.8$ & $33.3 \pm 32.5$ \\
$\mathrm{FEV}_{1} / \mathrm{FVC}, \%$ & $73.9 \pm 18.7$ & & $71 \pm 15.8$ & $70.3 \pm 15.1$ \\
Weight, $\mathrm{kg}$ & $51.9 \pm 9.4$ & & $52.6 \pm 8.8$ & $53.5 \pm 10.3$ \\
Height, cm & $153.7 \pm 19.3$ & & $155.2 \pm 16.2$ & $157.2 \pm 15.2$ \\
$\mathrm{BMI}, \mathrm{kg} / \mathrm{m}^{2}$ & $19.6 \pm 3.9$ & & $19.3 \pm 3.3$ & $19 \pm 2.9$ \\
Hospital visits & $2.9 \pm 2.5$ & & $1.9 \pm 2.1$ & $1.7 \pm 2.3$ \\
ED visits & $0.7 \pm 1.3$ & & $0.7 \pm 0.7$ & $0.5 \pm 1.1$ \\
Clinic visits & $7.9 \pm 3.8$ & & $7.2 \pm 3.6$ & $7.0 \pm 3.2$ \\
Oral antibiotics & $3.3 \pm 2.1$ & & $2.7 \pm 1.8$ & $3.2 \pm 1.3$ \\
IV antibiotics & $2.6 \pm 2.0$ & & $2.0 \pm 2.1$ & $2.1 \pm 2.4$ \\
\hline
\end{tabular}

Data presented as mean $\pm S D$. *Significant change $(P=0.024)$. BMI Body mass index; ED Emergency department; IV Intravenous; $F E F_{25-75}$ Forced expiratory flow over the middle one-half of the forced vital capacity (FVC)/forced expiratory volume in $1 \mathrm{~s}\left(F E V_{1}\right)$; pred Predicted

In the group, there were no significant differences in demographic or clinical characteristics between patients who underwent lobectomy secondary to recurrent hemoptysis or PTX, or both, compared with those who underwent this procedure due to severe worsening localized lung disease; however, the number of patients in each group was small.

The group was divided based on the severity of underlying lung disease, which was determined according to mean $\mathrm{FEV}_{1}$ during one year before surgery (Table 3). Patients with severe lung disease were those with $\mathrm{FEV}_{1} \leq 40 \%$ of predicted while patients with $\mathrm{FEV}_{1}>40 \%$ of predicted were classified as less severe. Demographic and clinical variables were compared between groups. One patient was two years of age; therefore, pulmonary function tests were not performed. All three patients who died were in the severe lung disease group.

Within the group with less severe lung disease $\left(\mathrm{FEV}_{1}>40 \%\right.$ of predicted), $\mathrm{FEV}_{1}$ at one year before surgery was $71.9 \pm 19.7 \%$ of predicted, which at surgery decreased to $65.1 \pm 23.4 \%$ of predicted $(\mathrm{P}=0.05) . \mathrm{FEV}_{1}$ at one year after surgery was $63.6 \pm 23 \%$ of predicted and at two years after surgery was $63 \pm 23.5 \%$ of predicted (Table 3 ). There was significant decrease in mean $\mathrm{FEV}_{1}$ from one year pre to at surgery $(-6.8 \% ; \mathrm{P}=0.05)$. Decline in mean $\mathrm{FEV}_{1}$ in first year after the surgery was $-1.5 \%$ and in second year after the surgery was $-0.6 \%$; neither were statistically significant. The rate of decline in mean $\mathrm{FEV}_{1}$ at surgery, at one year and at two years after the surgery were compared using paired $t$ tests and the differences were not significant.

In patients with severe lung disease, mean $\mathrm{FEV}_{1}$ did not change significantly between the three time periods $(-1.6 \%,-0.8 \%$ and $-0.2 \%$, respectively) (Table 3 ). In this group, the rate of decline was not significantly different among any of the time periods.

Compared with the patients who survived $(n=12)$, the deceased patients $(n=3)$ received significantly more oral antibiotic courses during two years before surgery (median 6 versus $4 ; \mathrm{P}=0.036$ ), had more days with a chest tube (median 14.5 versus $5 ; \mathrm{P}=0.018$ ) and a longer length of stay (median 23 days versus 10 days; $\mathrm{P}=0.04$ ).

\section{DISCUSSION}

Our study showed that in CF patients who require lobectomy, there were no significant changes in mean weight, BMI, hospital admissions or antibiotic use during the two-year period after surgery, and there was a continued decrease in mean $\mathrm{FEV}_{1}$ after surgery but the rate of decline improved after surgery in patients with less severe disease (ie, $\mathrm{FEV}_{1}$ $>40 \%$ of predicted); however, the differences were not statistically significant. There were three deaths within two years after surgery - all in
TABLE 3

Changes in clinical course from one year before to two years after lobectomy among patients with $\mathrm{FEV}_{1} \% \mathbf{> 4 0} \%$ of predicted (pred) and $\leq 40 \%$ pred at one year before surgery

Patients with $\mathrm{FEV}_{1}>\mathbf{4 0} \%$ pred at one year before lobectomy $(\mathrm{n}=\mathbf{8})$

\begin{tabular}{|c|c|c|c|c|}
\hline & \multicolumn{4}{|c|}{ Surgery } \\
\hline & 1 year pre & At surgery & 1 year post & 2 years post \\
\hline $\mathrm{FEV}_{1}, \%$ pred & $71.9 \pm 19.7^{*}$ & $65.1 \pm 23.4^{*}$ & $63.6 \pm 23$ & $63 \pm 23.5$ \\
\hline FVC, \% & $85.2 \pm 14.1$ & $76.9 \pm 19.7$ & $78.1 \pm 15.4$ & $77.9 \pm 15.3$ \\
\hline Height, $\mathrm{cm}$ & $151.9 \pm 23.4$ & & $154.7 \pm 18.8$ & $155.2 \pm 17.8$ \\
\hline Weight, kg & $53.2 \pm 12.1$ & & $55.1 \pm 10.9$ & $56.1 \pm 12.2$ \\
\hline $\mathrm{BMI}, \mathrm{kg} / \mathrm{m}^{2}$ & $18.5 \pm 3.2$ & & $18.7 \pm 3.1$ & $18.9 \pm 3.5$ \\
\hline Hospital visits & $2.0 \pm 1.5$ & & $2.1 \pm 2.1$ & $1.3 \pm 1.6$ \\
\hline Oral antibiotics & $3.3 \pm 2.0$ & & $2.7 \pm 1.7$ & $3.0 \pm 1.2$ \\
\hline IV antibiotics & $2.1 \pm 1.4$ & & $1.9 \pm 2.1$ & $1.6 \pm 1.8$ \\
\hline \multicolumn{5}{|c|}{ Patients with FEV $1 \leq 40 \%$ pred at one year before lobectomy $(n=4)$} \\
\hline $\mathrm{FEV}_{1}, \%$ pred & $34.8 \pm 5.6$ & $32 \pm 7.3$ & $31.2 \pm 8.9$ & $31.3 \pm 10.6$ \\
\hline FVC, \% & $50.1 \pm 8.4$ & $47 \pm 9.0$ & $46.7 \pm 10.7$ & $46.0 \pm 15.4$ \\
\hline Height, $\mathrm{cm}$ & $160.8 \pm 10.2$ & & $160.8 \pm 10.2$ & $160.8 \pm 10.2$ \\
\hline Weight, kg & $48.9 \pm 3.4$ & & $48.8 \pm 3.2$ & $48.9 \pm 4.1$ \\
\hline $\mathrm{BMI}, \mathrm{kg} / \mathrm{m}^{2}$ & $19.1 \pm 3.3$ & & $18.6 \pm 1.8$ & $19.1 \pm 1.7$ \\
\hline Hospital visits & $4.6 \pm 0.4$ & & $2.0 \pm 2.3$ & $2.6 \pm 3.3$ \\
\hline Oral antibiotics & $3.8 \pm 3.0$ & & $3.3 \pm 1.9$ & $4.0 \pm 1.2$ \\
\hline IV antibiotics & $3.8 \pm 3.1$ & & $2.8 \pm 2.2$ & $3.3 \pm 3.4$ \\
\hline
\end{tabular}

Data presented as mean $\pm S D$. *Significant change $(P=0.05)$. BMI Body mass index; FEV ${ }_{1}$ Forced expiratory volume in $1 \mathrm{~s}$; FVC Forced vital capcity; IV Intravenous

patients with more severe lung disease; thus, lobectomy should be avoided in patients with severe lung disease.

In CF, progression of lung disease plays a primary role in morbidity and mortality. Conservative medical management is essential to slow progression of lung damage from infection and/or inflammation; thus, pulmonary clearance with aggressive chest physiotherapy, nebulized mucolytics and aggressive antibiotic therapy are the mainstays of medical management of CF-related lung disease. Some patients develop progressive localized lung disease (primarily in the right upper lobe) that fails to respond to conventional therapies and, thus (especially if other areas of lung are less involved), surgical intervention is recommended to prevent disease progression in uninvolved areas (2). Some patients may require this procedure secondary to life-threatening complications of CF, such as PTX or hemoptysis, when conservative therapies fail. Very few studies, with a limited number of patients, are available on the utility of lobectomy in $\mathrm{CF}$, suggesting variable clinical benefits, and have also indicated increased morbidity and even death from the procedure (2-8). It is not clear which patients are better candidates for lobectomy. We undertook the present study to improve our understanding of the benefits and risks associated with this procedure by reviewing data from our CF centre.

The current literature suggests that some patients may experience improvement in either clinical symptoms and/or CF exacerbations after lobectomy; however, the results are inconsistent because the studies were performed in different eras, and patients in these studies varied in age and severity of underlying disease. Data regarding PFT is even more difficult to interpret for similar reasons. In a cohort of 23 patients undergoing surgery either for localized or extensive lung disease, Mearns et al (3) reported some clinical improvement in symptoms in the majority of patients. Similarly, in a cohort of 10 pediatric patients undergoing surgery mostly for abscess and bronchiectasis, Marmon et al (4) reported improvement in symptoms and a decrease in pulmonary exacerbations during a follow-up period ranging from six months to 13 years. In a cohort of 14 pediatric and adult patients with a mean age of 14.5 years (range three to 30 years), Smith et al (5) noted a significant decrease in the rate of hospitalization for pulmonary exacerbation. Their cohort had variable disease severity with $\mathrm{FEV}_{1}$ ranging 
from $11 \%$ to $88 \%$. Two patients died and, in the remaining 12 , there was a significant decrease in $\mathrm{FEV}_{1}$ during one-year follow up. In this series, all patients with a preoperative $\mathrm{FEV}_{1}<30 \%$ of predicted experienced a poor outcome. Their recommendation was that surgery in patients with $\mathrm{FEV}_{1}<30 \%$ of predicted should only be performed in life-threatening circumstances. In other smaller series, Steinkamp et al (6) (three patients) and Lucas et al $(7,8)$ (six patients) reported improvement in overall clinical status and respiratory symptoms after pulmonary resection for localized disease. Patients in the Lucas et al cohort were young, ranging from one to 12 years of age with localized severe disease, and many presented with stable or improved lung function at the four-year follow-up (8). More recently, in a cohort of 21 pediatric patients with mean age of eight years (range two to 17 years), Camargos et al (9) revealed no statistically significant difference when $\mathrm{FEV}_{1}$ at two years before surgery was compared with $\mathrm{FEV}_{1}$ two years after surgery. However, loss and a subsequent partial recovery of lung function were observed one to two years before and after surgery in patients with $\mathrm{FEV}_{1}>80 \%$ of predicted.

Comparing our data with the above studies, our cohort was older, with a mean age of 20 years. Patients had clear obstructive airflow physiology with mean $\mathrm{FEV}_{1}$ of $57 \%$ of predicted. In our cohort, there was ongoing decline in mean $\mathrm{FEV}_{1}$ with time both before and after the surgery. Interestingly, the annual rate of decline in mean $\mathrm{FEV}_{1}$ improved after surgery in the total group but was noted only in patients with less severe lung disease (ie, $\mathrm{FEV}_{1}>40 \%$ of predicted) and differences were not significant. In the total group and in either subgroup, no significant improvement after surgery was noted in PFT, hospital admissions or oral and intravenous antibiotic use per year. The three patients who died had more severe lung disease; thus, decisions regarding surgery should not be taken lightly in patients with CF, especially in those with $\mathrm{FEV}_{1} \leq 40 \%$ of predicted. In some patients with severe lung disease, lung transplantation can be considered as an alternative treatment to lobectomy.

The present study had many limitations including its retrospective nature, small sample size and lack of control group. Nevertheless, the results are still helpful in reviewing the outcomes of lobectomy in CF patients. Although prospective studies evaluating the utility of lobectomy in a large number of patients with CF would be helpful, conducting such studies would be difficult because this procedure is rarely performed in this population.

\section{CONCLUSION}

Lobectomy had no significant impact on PFT and disease progression. Poor outcomes were associated with $\mathrm{FEV}_{1} \leq 40 \%$ of predicted. In patients with advanced lung disease, this procedure should only be performed when all other measures fail.
ACKNOWLEDGEMENT/AUTHOR CONTRIBUTIONS: Shaid Sheikh, Karen McCoy, Nancy A Ryan-Wenger, Alpa Patel and Stephen Kirkby had full access to all of the data in the study and take responsibility for the integrity of the data and the accuracy of the data analysis. Dr Sheikh: contributed to the study design, study conduct, data analysis and interpretation, and manuscript preparation and serves as the guarantor of the manuscript. Dr McCoy contributed to the study design, study conduct and manuscript preparation. Dr Ryan-Wenger contributed to the data interpretation, data analysis and statistical analysis and manuscript preparation. Alpa Patel contributed to the study design, study conduct, data analysis and interpretation, and manuscript preparation. Dr Stephen Kirkby contributed to the study design, study conduct, data analysis and interpretation, and manuscript preparation.

DISCLOSURES: The authors have no financial disclosures or conflicts of interest to declare.

\section{REFERENCES}

1. Flume PA. Pulmonary complications of cystic fibrosis. Respir Care 2009;54:618-27.

2. Rolla M, D'Andrilli A, Rendina EA, Diso D, Venuta F. Cystic fibrosis and the thoracic surgeon. Eur J Cardiothorac Surg 2011;39:716-25.

3. Mearns MB, Hodson CJ, Jackson AD, et al. Pulmonary resection in cystic fibrosis; results in 23 cases, 1957-1970. Arch Dis Child 1972;47:499-508.

4. Marmon L, Schidlow D, Palmer J, Balsara RK, Dunn JM. Pulmonary resection for complications of cystic fibrosis. J Pediatr Surg 1983;18:811-5.

5. Smith MB, Hardin Jr WD, Dressel DA, Beckerman RC, Moynihan PC. Predicting outcome following pulmonary resection in cystic fibrosis patients. J Pediatr Surg 1991;26:655-9.

6. Steinkamp G, von der Hardt H, Zimmermann HJ. Pulmonary resection for localized bronchiectasis in cystic fibrosis. Report of three cases and review of the literature. Acta Paediatr Scand 1988;77:569-75.

7. Lucas JS, Connett GJ, Lea R, Rolles CJ, Warner JO. Lung resection in cystic fibrosis with localized pulmonary disease. Arch Dis Child 1996;74:449-51.

8. Lucas JS, Connett GJ, Fairhurst J. Long term results of lung resection in cystic fibrosis patients with localised lung disease. Arch Dis Child 2002;86:66.

9. Camargos P, Le Bourgeois M, Revillon Y, et al. Lung resection in cystic fibrosis: A survival analysis. Pediatr Pulmonol 2008;43:72-6. 


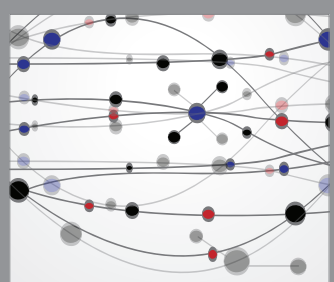

The Scientific World Journal
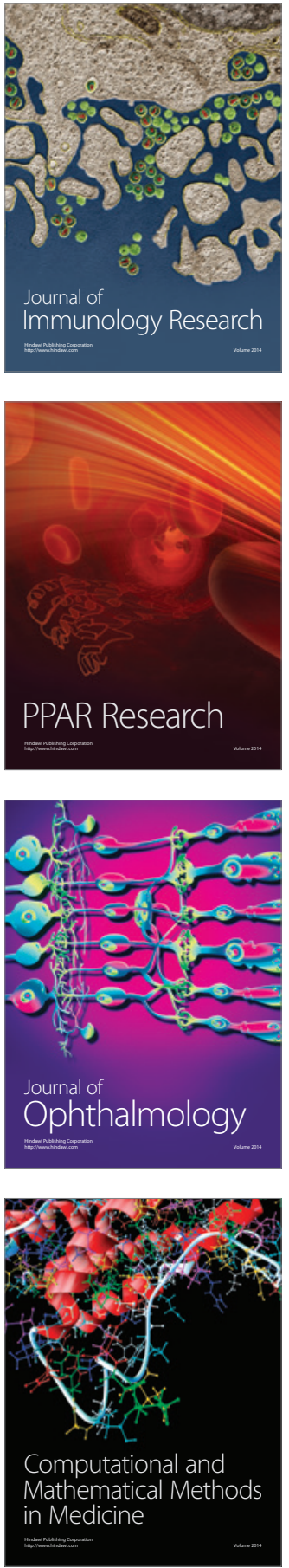

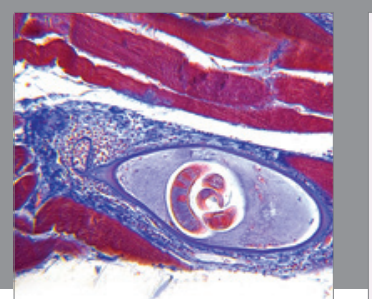

Gastroenterology Research and Practice

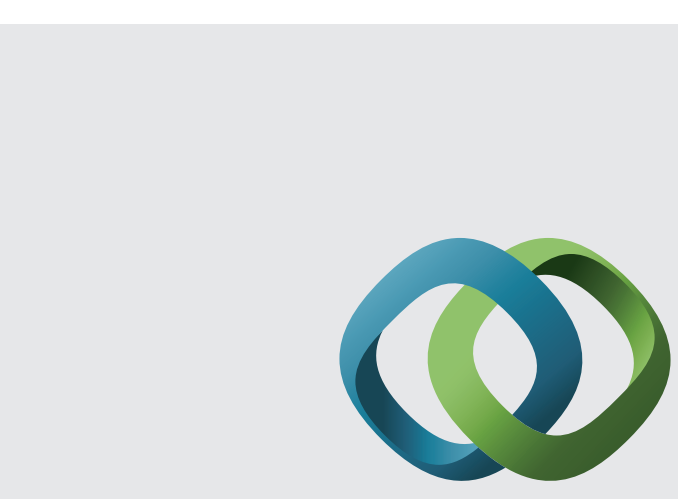

\section{Hindawi}

Submit your manuscripts at

http://www.hindawi.com
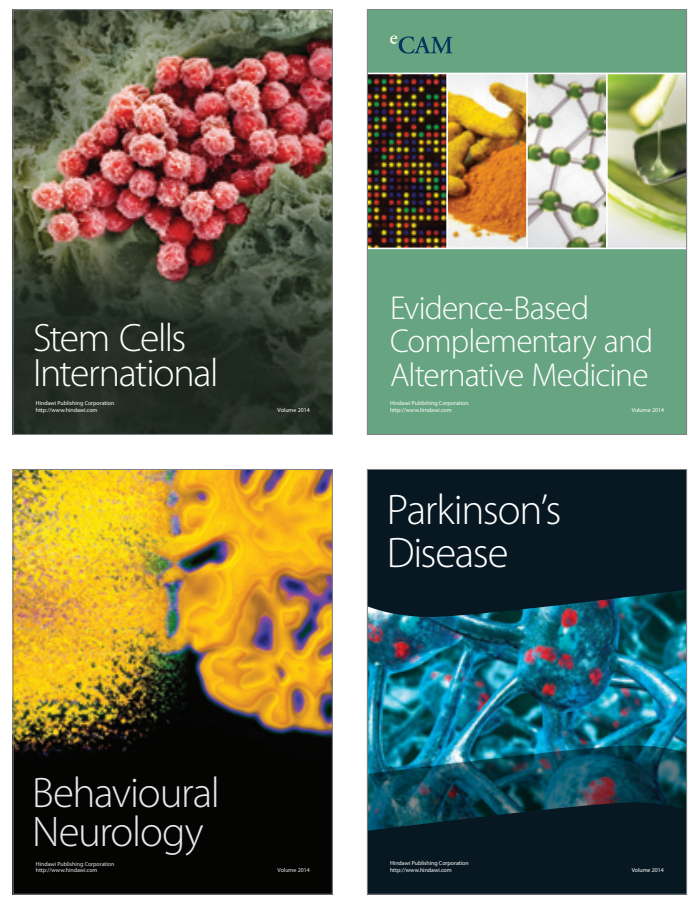
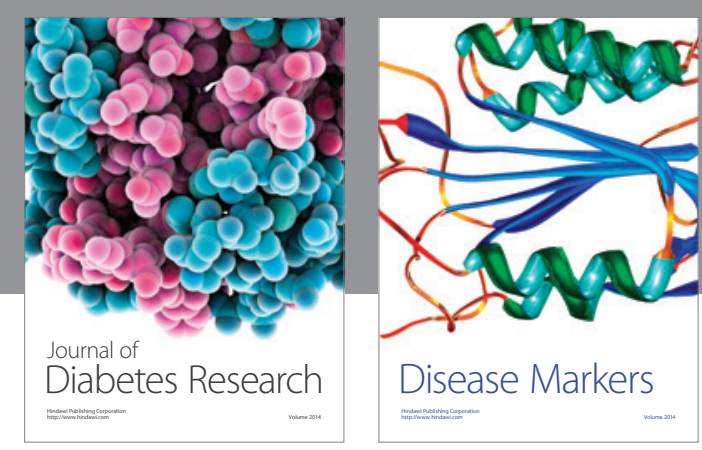

Disease Markers
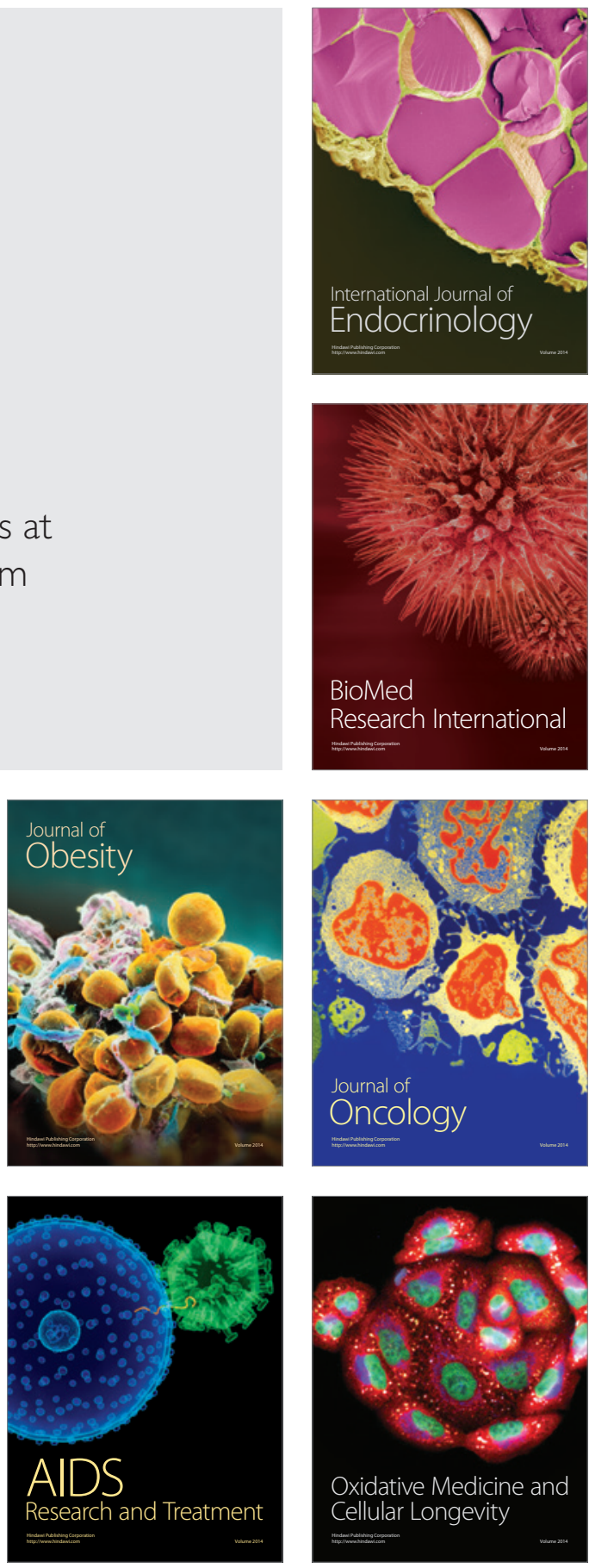